\title{
Embodied experiences of place: A study of history learning with mobile technologies
}

\begin{abstract}
This paper reports an empirical study that takes a multimodal analytical approach to examine how mobile technologies shape students' exploration and experience of place during a history learning activity in situ. In history education, mobile technologies provide opportunities for authentic experiential learning activities that have the potential to re-mediate students' understanding of space and place through enacted interaction, and to make the learning more memorable. A key question is how learners work with the physical and digital information in the context of that learning experience, and how this supports new experiences and understanding of space and place. Findings suggest that embodied mobile experiences foster the creation of both physical and digital markers, which were instrumental in concretising the history experience and developing new narratives. The findings also show how different representational forms of digital information mediated interaction in specific ways and how digital augmentation can lead to conflation in student understanding of space and time. These findings inform our understanding of the value of mobile applications in supporting embodied learning experiences and provide key implications for pedagogical design, both in situ and back in the classroom.
\end{abstract}

\section{Keywords}

Physical-digital interaction; embodied learning; mobile technologies: iPads; history learning 


\section{Introduction and background}

Mobile technologies and location-aware computing that enable access to contextually relevant information through digital augmentation, have been shown to enhance and change user interaction in the real world (Herodotou et al., 2014; Järvelä et al., 2007; Jones et al., 2003; Rogers \& Price, 2008). This offers opportunities for augmenting real-world environments to differently engage learners with subject related material and with one another. Through digital augmentation and location-sensitivity, mobile technologies expose learners to various associations with a space, shape interactions differently and thereby lead to new meanings, identities and memories (Mills \& Comber, 2013). A sense of 'place' is developed through embodied experiences of a space that is imbued with cultural and social associations (Farman, 2012). Little research has, however, focused on examining learners' embodied interaction during mobile experiences of place and how these shape the unfolding learning process.

In the context of history learning, digitally augmented experiences of place can 'bring closer' aspects from the past, enabling student engagement in location with different time periods simultaneously. Digital augmentation enables "the meanings of places [to be] augmented by data overlays" (Farman, 2012, p.39). Lerner (as cited in Jones, 2010) has highlighted the beneficial role of photos and artefacts in making "history more meaningful and emotionally relevant" (p. 124). Mobile technologies construct a direct relationship between the user's physical environment and the information they are receiving and producing (McCullough, 2006), giving opportunities for students to think about relevant physical stimuli in their surroundings with reference to the digital stimuli, and vice versa.

Configurable apps increasingly offer opportunities for educators to design their own learning experiences using location-based mapping capabilities (e.g. HistoryPin, Locacious and PinMap). 
These are important in facilitating increased use of mobile technologies in education and fostering pedagogical approaches that support experiential forms of learning in authentic environments. At the same time, such environments raise pedagogical challenges for teachers in terms of how best to present and enable the creation of digital information as part of the learning experience. For example, different modes of digital information have distinct potentials and constraints in communication and interaction (Kress, 2010) and raise questions about whether certain types of digital augmentation are more suited than others to supporting particular types of learning (Jewitt, 2014; Price et al., 2008). Insight into these aspects of digital learning environments is critical to the design of learning activities around mobile devices, and understanding learning in these multimodal spaces. There is, however, a lack of research that examines how the different representational forms of digital augmentation shape action, interaction and reflection during a digitally augmented mobile learning activity. A key question is how learners use and link this digital information with physical information: what physical information they attend to in relation to the digital, how they interpret the physical in the context of the digital information, and how this shapes their understanding of 'place'.

Mobile technologies have moved digital activity away from the desktop into everyday anywhere interaction. Such technologies have an impact on the production of social and embodied space through engaged interaction and emerging practices. Mobile computing has thus brought new thinking and discussion around concepts of space, place and embodiment. It "has transformed embodied space in the digital age" (Farman, 2012 p.19), and fostered notions of embodied interaction as "the creation, manipulation, and sharing of meaning through engaged interaction with artifacts" (Dourish, 2001 p. 126). The concept of embodied interaction highlights the 
importance of the body and embodied experiences in engaging with and making sense of the world around us (Dourish, 2001; Goodwin, 2000; Streeck et al., 2011).

For education this capacity of mobile technology provides important experience-based learning opportunities that are socially and culturally situated. They also support a learning by doing pedagogy that requires reasoning and reflection (Norris \& Soloway, 2013) in authentic learning activities or environments (e.g. Lombardi, 2007), and provide scaffolding that is important in enabling students to learn in real world contexts (Hwang, 2013). A major challenge for education is in designing "learning experiences and activities for learners to construct knowledge by engaging and inspiring them to learn" (Milrad et al., 2013 p. 106). Empirical research has a critical role to play in understanding how such embodied learning activities unfold and are reshaped by mobile technologies.

Over the last ten years a range of studies have explored mobile technologies and place-based learning (e.g. Huizenga et al., 2009; Jones et al., 2003; Martin et al., 2012; Rogers \& Price, 2008; Vogel et al., 2010; Williams et al., 2005). However, findings primarily focus on learning opportunities offered by digital augmentation with mobiles in situ, the role of context in supporting learning, enjoyment and ease of experience. However, increased interest in bodily interaction and theoretical notions of embodied cognition in the context of emergent technology highlight the need to gain better insight into how the learning process is shaped by digital augmentation through mobile technologies, and the role of the embodied experience in contributing to developing an understanding of historical 'place'. Changes in mobile technology capability and the spatial interactive practices that they give rise to, together with aspirations for increasing socio-constructivist and learner-driven pedagogies in education, raise a number of methodological challenges. Studies tend to use recall tests to determine the extent of location 
knowledge, critical incidents to analyse issues around pedagogy, design-based research through participant workshops (Jones et al., 2003), or quasi-experimental methods to examine learning outcomes (e.g. Huizenga et al., 2009). However, quantitative analyses of pre- and post-test measures do not (and are not designed to) elucidate the interactional processes, the role of the body in developing the experiential process, nor the specific interaction with technological features that are important in shaping interaction. In contrast, this study, based on observation, adopts a multimodal analytical approach that foregrounds bodily action and movement, context and digital augmentation, and how the different modes of communication (gesture, gaze and bodily position) come into play, in order to gain purchase on the role of the embodied experience - through both digital and physical engagement with the learning topic and environment.

\section{Method: Study design}

\section{Research questions}

This research took an exploratory case study approach to investigate how mobile technologies mediate students' exploration and sense of place, and understanding of history in situ. The key research questions include:

- How does a digitally augmented mobile activity enable students to re-experience space as a 'place' with new meaning?

- How do students work with or integrate digital and physical information to think about and make sense of the history of that place?

- What digital tools, characteristics or features are important in helping them construct or re-create a sense of place? 
To achieve this, a learning activity was designed, implemented and evaluated through observation and analysis of video data of students' learning interactions and processes, using mobile technologies in situ.

\section{Activity design}

The activity was designed to engage students in an exploration of the experiences and events of the Second World War (WWII) that were directly associated with their local Common. This is a large space with open grassy and wooded areas. It is interspersed with paths, and divided in one place by a small road. It is bounded by main roads, and surrounded by city housing and shops. The activity was designed in conjunction with the class teacher to fit with and enhance the history curriculum learning on WWII that takes place in Year 5. The design aimed to support in situ experiences of place through digital augmentation that supported the linking of spaces, events and experiences across time and to support paired working to promote dialogue and shared experiences.

The activity was based around Evernote, which is freely available and easily configurable by everyday users, making it accessible to teachers. In the version used at the time of the study it enabled the creation and presentation of digital artefacts (texts, photos and audio notes), which could be linked via GPS to specific physical locations, and provided the facility for students to make their own digital artefacts during interaction. Fourteen digital notes were positioned on a map of the Common for students to access during the activity. These included distinct sets of photographs, drawings, and written testimonies from the local historical society, and sound clips from online sound archives. Each note related to historical events that took place in that location during WWII. For example, one note contained a photograph of people in one of the deep shelters that were built under the Common, as well as some written testimony that described the 
experiences of staying in the shelter. Written prompts were used with some notes to encourage students to actively engage with people's past experiences and compare them with their own. Notes were represented by flags on the digital map of the Common (Figure 1) and were positioned relevantly to the information contained in the notes. For example, notes that related to the church were positioned beside the church; those relating to the deep shelters were located above the area of the shelters' location.

Figure 1. Flags positioned on the map of the Common

While novelty was not controlled for in the study, all of the students had used an iPad before, and our observations did not suggest that novelty was a central feature of their interactions.

\section{Participants}

Sixty students from Year 5 (aged 9-10 years) from a London primary school took part. Thirty two had written parental consent and gave their own verbal consent to participate in the research (in line with British Educational Research Ethics guidelines). Thus analysis is based on 16 student pairs. Pairs were selected by the teacher on the basis of being able to work well together, in order to foster collaboration and joint activity.

\section{Procedure}

Over the course of two days all 30 pairs took part in the activity, with five pairs of students engaged in the activity at one time (15 pairs on each day). The remaining students were provided with a drawing activity and a ball game organized and supervised by the teachers, on a separate part of the common from the activity. Immediately prior to doing the activity each pair received a five minute demonstration of the app, where they had the opportunity to practise accessing and creating 'flags' by taking photographs, making audio recordings and writing captions. Most students were familiar with the iPad, and this length demonstration was sufficient for them to use 
the app competently throughout the activity with no or minimal prompts. After the demonstration the pairs had 25-30 minutes to explore the Common, using the Evernote activity as they wanted. A researcher accompanied each pair to capture the exploration on video with a handheld camera, acting as a facilitator to support safety, technical use and encourage on task activity.

\section{Analysis}

Multimodality provides the analytical frame for this project (Jewitt, 2014; Kress, 2010). It provides a fine-grained understanding of interaction-in-context through the study of people's modes of interaction and investigates the implications of this for meaning-making. In particular it emphasizes situated action, and provides concepts, methods and a framework for the collection and analysis of visual, aural, embodied and spatial aspects of interaction and environments.

\section{Table 1: Example transcript}

Analysis was conducted on video data from the 16 student pairs' explorations. Video data was transcribed to record different modes of interaction including movement through space, body action and orientation, gaze, gesture, interaction with the iPad and the environment, and talk (Table 1). 'Movement' recorded whether participants were standing still, walking, running or turning. 'Interaction with the iPad' recorded how students were engaged with the application e.g. whether they were accessing a note, which note was accessed, or creating a note of their own. 'Body action' recorded all other interaction such as pointing, gesturing or lifting the iPad to frame the environment. Students' talk was recorded along with the researcher's interaction. Transcribing these modes of interaction in this way enabled patterns to be seen across the multimodal interaction. Themes and categories were refined to focus on place and embodied interaction. For example, it was possible to consider how patterns of movement were constrained or facilitated by interactions with the application e.g. whether students were more likely to be 
standing still when they engaged with the app or continuing to do so on the move. Patterns in students' attention to the physical in the context of digital information were identified and the relationship between engagement with digital notes and digital creation. Analysis also focused on moments of engagement with digital notes to examine how the notes were used in the context of the task: what kind of bodily interaction or kinds of talk they encouraged. The data was analyzed thematically through iterative collaborative viewing of the video data by the research team and engagement with the transcripts of interaction. Features of interaction that relate to physicaldigital engagement were identified from activity that occurred among the majority of student pairs, although findings are illustrated with reference to particular examples to demonstrate the phenomena.

\section{Findings and discussion}

All students enjoyed the activity and engaged readily with the iPad, quickly becoming proficient at using the app. Digital information was found and accessed in relation to specific physical locations across the Common. All students responded to their engagement with the digital notes and their experience by creating their own visual and audio artefacts about the Common. Analysis revealed four key characteristics that provide insight into their learning process with physical and digital information and experience, the role this has in meaning making and the interpretation of historical experiences, and the re-shaping of their understanding of 'place'.

The students' use of the flags to determine their movement on the common foregrounded the significance of the specific physical locations in the environment in which the digital information was located. This shaped the way that students attended to the physical information and the links they made to the digital. Digital notes were accessed 69 times across all pairs of students, with each pairs' access varying from $2-7$ digital notes (table 2). 
Table 2: Distribution of digital note access across student pairs

\section{Creation of physical indicators: Grounding the digital in the physical}

The majority of pairs were observed to search for physical indicators of historical sites or events that were displayed through the digital notes. In some locations these historical sites or physical indicators were self-evident, for example, bomb damage to the church is preserved on the church wall and a war memorial in the form of a stone cross with a plaque. However, where no specific physical indicators were present students sought to 'ground' the digital events or ideas in the physical, by attributing physical features of the environment to the digitally accessed information, evidenced through the following examples.

Fourteen of the sixteen pairs sought physical evidence of war time features, the allotments, bomb damage, or where military training took place. Six pairs picked out old buildings or related artefacts (i.e. the memorial) around the Common as indications of 'war'. Nine of the pairs looked for damage to buildings, and specifically the church, which had bomb damage preserved on the wall. Four pairs examined the ground for bomb craters, attributing the current concrete paddling pool as a bomb crater, or seeking irregularities in less obvious markers, such as damaged areas in the tarmac or paving, or bare areas of grass. In the wide-open area of the Common students accessed digital notes about the bomb shelters that exist underneath this part of the Common. Although the deep shelters ran underground, students looked for physical signs above ground for evidence that the shelters existed, making statements like "It should look like there was a hole and they covered it up". Three pairs suggested a bare patch on the grass or identified a large hole in the tarmac pavement as evidence of the shelters underneath. One student even bent down to feel the temperature of the ground when the other was reading from a digital note that the floor was cold in the bomb shelter. 
After looking at the note with the image of people in shelters (Figure 2), Pair D linked the shelters with a larger visible landmark on the common: the skate park, "I think that skatepark was a shelter and because there isn't a war now, they've changed it into a skatepark for people that want to have fun".

Figure 2: Photograph 'Sleeping in the deep shelter'

A different pair (pair K) singled out a plantation of trees as the location where soldiers had trained, and thought about sticks that they found in relation to 'stick grenades' from the war. Another (pair M) located a crack along the ground as the place where the guns had been (Figure 3). In these instances the physical environment appeared to be acting as a trigger to both imagine and concretize concepts of war in situ.

Eight pairs accessed a digital note with a soundscape of soldiers marching on the Common. Four of these pairs $(\mathrm{E}, \mathrm{H}, \mathrm{K}, \mathrm{M})$ linked this directly to a specific area of paving on the grass as the location where the soldiers marched in the past i.e. did their training. This 'place' for soldiers marching was imagined and, in effect, 'false' since this paved area was designed for vehicles in present times to access the Common. While this link can be seen as 'false', it played an important role for the students in enabling them to take a tangible, embodied 'grasp' on their learning about war.

\section{Figure 3: Photograph 'Guns on the Common'}

These examples show how students actively sought physical features or landmarks of the present day environment to directly link to digital information. By linking environmental features with historical information accessed digitally, the learners were attributing new meaning to these otherwise everyday features in the environment. This resonates with Farman's (2012) argument 
that the materialities of space act as a foundation for making meaning, highlighting the role that the creation of physical indicators play in students' development of a new narrative of 'place'.

Grounding their conceptions of the past in this way is critical in enabling them to think in concrete ways about perceived differences in experience between now and then. By focusing on the skatepark, the pair in the example above gave themselves a visual focus, which then became the subject of a photograph that prompted further comparison and reflection on life during WWII. Even though these entities do not exist simultaneously, students are in effect giving equal weight to the physical and the digital (Milgram \& Colquhoun, 1999), yet at the same time 'folding' the digital information into the physical (Manovich, 2002). The juxtaposition of these physical realities enabled students to contrast experiences of WWII and the present day.

The creation of physical markers illustrates how students manage different layers of experience and develop an understanding of historical 'place' that is based on both new and known information. This connection to the 'physical' enables them to create new meanings in otherwise familiar places (Farman, 2012). In this way physical indicators act as a kind of place-holder or artefact to provide an 'anchor' for historicized imagination: a way to identify and remember. This phenomenon relates to theories of the 'extended mind' (Clark \& Chalmers, 1998), one aspect of which proposes that "the world is an external store of information relevant to processes such as perceiving, remembering, reasoning..." (Rowlands, 2010 p. 59). In the case of the students the physical markers created then become artefacts in the environment, which hold information that can be transformed or linked directly to their learning experience and used as place-holders for remembering.

Table 3: Number of physical markers and digital artefacts created by student pairs 


\section{Creation of digital artefacts: Linking the physical to digital}

Students also created their own digital artefacts in the form of photographs, audio recordings and typed notes. This creation of digital artefacts facilitated active comparison between their present experiences and those of people living in the past. Across all students 103 artefacts were created: 58 photographs, 42 audio recordings, and 3 written notes to record their reflections about the history activity. Of the 69 instances when they looked at pre-prepared digital notes, in the majority of cases (49) they created their own digital records immediately afterwards. The creation of photographs served different purposes. In many cases they represented a record of their 'creation of physical markers' (described above). For instance, craters in the ground, a bare patch of grass, the war memorial and bomb damage on the church. These were taken in response to digital notes accessed about the war, for example, the bombings on the common. Digital artefacts were also explicitly created to illustrate differences on the common between their present time, and the time illustrated in the digital notes accessed. For example, Pair E took a photograph of someone on a uni-cycle in juxtaposition to the image accessed of soldiers training on the common. Another pair (Pair J) took a photograph of people walking dogs and buses going by to contrast their own experience with that of Margaret's in the shelter. Students took photographs of the war memorial to accompany verbal reflections on the experience of WWII for those living near the Common; or the wide-open spaces of the Common to emphasise the 'greenness' of the space and the lack of military paraphernalia, like the 'Guns on the Common' (Figure 3), and to portray ideas of being calm and safe in the present. For example, after looking at the digital note with the image of the shelter (Figure 2) and reading Margaret's testimony (Figure 4) Pair J took photographs of dogs in the park and talked about hearing "birds tweeting and people talking and the cars, instead of hearing frightening things like gunshots". Thus, digital artifact creation was 
commonly provoked by engagement with pre-designed digital notes, but served to support students in thinking about differences between past and present.

Figure 4: Written testimony - Margaret Barford's experience of sleeping in the shelters Creating audio notes to accompany the photographs taken was commonly used to articulate and elaborate their comparisons between past and present, and fostered descriptive narratives of activity and landscapes based on their current surroundings (Table 4).

\section{Table 4: Examples of audio narratives}

Audio notes were also used to express feelings and emotional aspects of 'experience' on the common in present time as well as past, and imagining how people from the WWII era may have felt.

Pair C: "I would enjoy working on the allotments because it would make me proud and happy to work for a church and to make other people happy and make myself happy and it's a very good work-out."

Or expressing comparisons in terms of negative or positive experiences:

Pair D: "These sounds we hear now are quite positive whereas the ones in the olden times seem quite negative, so I think there's a huge difference in what we hear,"

Pair E: 'I don't think that people feel like soldiers because there's no war going on and they come here to have fun and relax, whereas the soldiers came here to get a de-briefing from their leaders and got very bored of fighting and dying."

However, student artifact creation also revealed how preconceived ideas and experiences could colour their perspectives. In the note 'Margaret's testimony', she talks about how they couldn't hear the sounds of war in the shelter, and foregrounds other sounds like laughter and music. 
Despite this, students tended to talk about differences that related to negative or frightening aspects of the war. This suggests that students' preconceived ideas about war dominated their interpretations of information, even when given contradictory evidence. In line with theories of conceptual learning (e.g. Chi, 2008) and multimodal social semiotic theories of interest and semiotic chains of meaning (e.g. Kress, 2010), this demonstrates the power of students' own articulations of a concept relative to external representations of the concept. Making artefacts in the form of notes gave students a way to reinforce and express their own articulations of war.

The process of creating digital artefacts illustrates how students weave together the digital and the physical to connect different layers of experience and to foster a simultaneous engagement with the past and present. Farman (2012) highlights a difference between 'information as data' versus 'narrative'. Data is information that is static and exists in isolation; through personal interactions with data, meaning is generated and narratives are created. Through creating their own digital artefacts, students made historical narratives with the 'data' they were interacting with, that led to a reconstruction of narratives about the familiar place of the Common. This has two key effects. Firstly, in doing this, students have experienced something new and made new memories or narratives attached to this location - a location they pass through on an everyday basis. As such their notion or sense of that place will have been re-shaped. This is likely to foster their engagement with and memory of their learning about WWII, more than if they had engaged only with disembodied-decontextualised 'data' in the classroom. Secondly, the site-specific media they experienced provided a direct juxtaposition to their current sensory experience of the common, enabling clearer awareness of differences between the two periods of time. Something that would not so easily be achieved through engaging with similar media and narratives in the classroom, which removes that 'lived' experience. This type of comparison was more evident 
when photographs were taken, than when audio recordings were made - the latter often reiterating previously held assumptions, rather than making direct comparisons.

Figure 5: Note: 'Reverend's letter'

\section{Digital representational modes}

Students' engagement with the different digital stimuli shaped the action and interaction that followed. Their engagement differed in length and character, and led to different forms of participation.

When students engaged with a written stimulus, such as the Reverend's Letter (Figure 5), the majority of time was focused on reading the letter out loud and 'getting to the end', rather than reflecting on the experience it described or its relationship to present physical surroundings. This was particularly problematic for students who experienced difficulty reading - a problem not encountered with the other representational modes. In contrast when students engaged with visual stimuli (e.g. photograph of people sleeping in the deep shelter), the majority of their time was invested in reflecting on ideas that were stimulated by the photograph, imaginative engagement with the past that fostered an ability to think about differences in terms of experience, rather than solely facts. For example, thinking about the past and re-imagining the present environment within that context. Pair L looking at the photograph 'Guns on the Common' (Figure 3) identified the wide open space of the Common as somewhere spacious where guns could be placed to counter attack any bombs being dropped in the area. Their focus on bombs being dropped was mediated by the previous image they engaged with, which was of the bomb shelters underground (Figure 2). This example, also serves to illustrate how students linked information across the digital notes accessed, and used them to build up a richer picture of the past. Other pairs (e.g. pairs $\mathrm{B}, \mathrm{C}, \mathrm{D}, \mathrm{N}, \mathrm{O}$ ) used the note with the image of the shelters as a basis from which to describe 
how life might have been in the shelters and to contrast this with their current experience. Images have been shown to be important in fostering new interpretations and understanding of history and offering critical views of the past (Berry et al., 2008). According to Berry "visual evidence must come from the margins to the center of historical inquiry due to the value images have in terms of memory and long-term learning" (p.438) where "emotionally provocative images can enhance memory retention of related historically-based content" (p. 445). The mobile learning environment activity in this study shows new ways that this can be realised i.e. the placing of such materials.

Students responded differently through their physical action and the extent to which the current physical environment was foregrounded in their response. In particular, the digital note with the audio of soldiers marching encouraged students to engage with this material through bodily enactment, involving the students' own dramatic physical marching movement around the Common. Audio stimuli have been found to offer alternative ways of thinking about events through sound, which can convey concepts of activity and movement in specific ways (Ardito et al., 2012: Williams et al., 2005). Sensory actions, like listening, have also been found to enhance children's awareness of the environment (Mills et al., 2013). Listening brings sound to their attention, and enabled the students to make comparisons of what they could hear in the present with what people in previous times may well have heard, and in the process offered a sensory imagined experience of the past. In contrast, when responding to the visual and written stimuli, students tended to remain still and close to the iPad, engaging with the Common via gaze and gesture rather than expansive bodily movement.

Collectively, these findings suggest that noted differences in the way that images and writing are organized and comprehended (Kress \& van Leeuwen, 1996; Price et al., 2008) impact on how they are responded to when used to support in situ learning. This analysis illustrates how different 
modes of representation serve important functions in embodied interaction, and raise further questions about the degree to which different augmentations might better support embodied experiences or feelings of presence through the digital. Nevertheless the findings suggest how different representational stimuli facilitated linking between the past and the present, and the type of conceptual relationship that the students constructed between the history of the Common and their present experiences. Being in situ triggers different meaning making and development of the concepts of place in relation to events, verifying the claim of mobile embodiment theory (Farman, 2012) that situatedness is critical in mediating new experiences. Thus being in situ enabled students to experience pictures/listening to audio differently from doing the same within the classroom where they can only imagine out of context.

\section{Conflation of space and time}

In a history based learning activity concepts of time are relevant to location. This raises questions about how students interpret events that took place in the same location but at different times in history and how they map information across present-day time and historical time. Analysis showed that students engaged in integrating time-related information, and that almost all pairs commonly conflated different time points in history during the activity. Although this is not surprising, since at the age of 9-10 years students' chronological understanding of the past is likely to contain many gaps (Haydn, 1999), it is significant in how it shaped the way that students used both physical and digital information in their exploration, and highlights implications for future design. Three key aspects contributed to conflation of time: physical proximity, physical or digital prompts and prior knowledge,. 


\section{Proximity}

The proximity of physical objects that clearly related to wartime to the flags linked to digital information on the iPad was influential on the links that students made. Notably, the physical proximity of location-based digital information led to an assumed chronological proximity of the events and experiences described. For example, Pair G assumed that a WWI memorial commemorated individuals from WWII mentioned in the digital notes linked to a nearby flag on the iPad. In addition to conflating WWI and WWII, the information in the digital environment was also close to another flag providing information about the allotments in WWII (Figure 6) and led the students to believe that the creation of the allotments was causally related to the memorial: i.e. that the individuals' pictured working on the allotments had died in the process and were publicly remembered through the physical war memorial. The students took these points of information and heightened the relationship between them in order to forge a narrative about the war, thus conflating time and space across the digital and the physical to create a 'plausible' narrative.

\section{Figure 6: Photograph 'Working on war-time allotments'}

\section{Physical and digital prompts}

While students used the Evernote map to guide their locative exploration of the Common, they also drew on physical clues in the environment that they associated with potential historical evidence. This included a search for time-orientated connections between the physical environment and the digital information, which sometimes led them to choose sites of interest on the Common that they considered to be 'old'. Pair A, for example, were walking between flags on the map, and in the absence of any digital prompt sought what they considered to be other task-relevant stimuli, such as an 'old' looking building. This demonstrates ways in which 
students predicted relevance of features based on a singular idea of the past and its physical manifestation through simply 'old' artefacts and buildings, and typically resulted in them talking about the past in a generic way.

These examples illustrate common issues of integrating prior knowledge with new knowledge, and highlight the complexities that can arise when integrating digital information about the past with current physical locations that exploit experiential interaction with the environment. The physical location differs fundamentally in how it looks, feels and how it is used in the different time periods, requiring students to work with several layers of knowledge. The digital prompts through audio and images provided a 'picture' of WWII history that had to be imagined, and therefore not necessarily easily distinguishable from other historical time periods. When the digital did not provide a clear guide as to what constituted task relevant elements in the physical environment students engaged in reimagining the 'old' through physical remnants of the past. Through doing this, they were in a sense constructing their own equivalent to the provided 'digital layer'. Thus, while the digital enabled students to record ideas about historical experiences relevant to the task, it also enabled them to add things that were not immediately 'relevant' to the learning activity. This raises questions about how to design digital prompts in relation to other historical periods to dissipate student conflation of time. It also how such interests, which may be seen as 'irrelevancies' or 'misconceptions', play out in the pedagogical space: for instance, how they can be used and managed productively in the classroom. In learning and teaching contexts, for example, such digital layers and records can provide teachers with important insights into the interests and thought processes of the students, offering a sound basis for mediating conceptual change (Winters \& Mor, 2008). 


\section{Prior knowledge}

Typically learning comprises linking prior knowledge with current experience. At times during interaction in this experience students demonstrated how their linking of various layers of knowledge led to confusion in the way that they imagined the past. Pair $\mathrm{K}$, on noticing women in the image 'Guns on the common' (Figure 3), immediately identified them as being suffragettes, conflating different time related historical events. Here the students' engagement with previous incomplete knowledge served to conflate historical ideas.

The observations regarding the conflation of time highlight the work that students have to do in order to integrate different layers of knowledge and experience in a learning activity like this, as well as the relationships they are constantly forging between the physical and digital environments. This emphasizes the 'coupled nature' and 'folding' (Manovich, 2002) of space, but also demonstrates how different interpretations of the past and present are 'folded' within each other in students' historical understanding and imagination.

\section{Conclusion}

The findings show how the integration of physical activities and digital information can lead to new embodied experiences of history and support new perceptions of a sense of place. The experience of the physical site in conjunction with the mobile digital overlay (both provided and created) supported new 'imagined' ideas and experiences of historical events that were grounded or made tangible through the in situ experience, and thus brought new meanings to that place. Engaging with digital media in situ enabled students to build a new of concept of 'place' that included their perceptions and interpretations of life during WWII. By creating physical markers that act as place holders for particular information, learners were dynamically changing their construction of the place in which they were in, and re-shaping the associations that they had with this place. By creating digital artefacts students developed new narratives about the location, 
which contributed to a new sense and understanding of place, and served a role in supporting established memories of historical events or experiences.

The findings have implications for pedagogy and informing the design of learning activities with mobile technologies. Mobile experiences like this can foster embodied forms of learning, in which experience grounds historical learning in new and more concrete ways. Furthermore, an increasing number of free applications exploit the ability of mobile media to organize and access data with site specificity, and are readily accessible to educators. However, such organization and access to data requires designing and tailoring to the needs of the teaching and learning. This study informs two key aspects of design.

Firstly, the design of digital artefacts is informed by observations of student interaction with image, text, sound and accompanying prompts. Written text needs to be designed and used according to reading ability, but can be substituted with audio of narratives, in conjunction with image in ways that overcome this limitation. To support enactment and foster imaginative engagement, audio recordings of topic relevant sounds can be effective, while images offer a visual route into conceptualizing ideas that directly corresponds and contrasts with visual experiences in the current context.

Secondly, since the creation of physical markers in relation to digital information is valuable in making the experience tangible and providing support for sustained recollection, then designing tasks or prompts to engage students in identifying these and making their own digital records is recommended. However, the findings also showed that this concretisaton of imagined aspects can lead to conflations that constitute a distortion of the past. This in turn indicates ways in which embodied, exploratory experiences in situ can be enhanced through classroom learning that gives learners an opportunity to reflect on the new understandings they have constructed, and check 
these against others' interpretations of the past. For example, engagement with physical markers and creation of digital artefacts would serve as a useful a starting point for a classroom based learning activity that forms the basis for further reflective work and deeper examination and analysis of these indicators and artefacts. The digital environment can begin to support these reflections by enabling students to listen back to the audio recordings they have made and view the pictures they have taken, and to use these to prompt and support productive discussions about what they demonstrate or show. Furthermore, collective viewing and sharing of student created digital artefacts would provide them with access to different interpretations of the common, from different student perspectives built on different identities and experiences, that is helpful for learning in general, and history learning in particular especially if part of the discussion and debate concerns what is significant to understanding the past. In this sense, mobile learning experiences provide important links between experiential and classroom-based learning.

\section{Acknowledgments}

This research was supported by ESRC NCRM (RES-576-25-0027). We would like to thank all the staff and children from the London Primary School that took part in this study, and to Kate Cowan and Anna Waring for their help in data collection.

\section{References}

Ardito, C., Costabile, M. F., De Angeli, A., \& Lanzilotti, R. (2012). Enriching Archaeological Parks with Contextual Sounds and Mobile Technology. ACM Transactions on ComputerHuman Interaction (TOCHI), 19(4), 29.

Berry, C., Schmied, L. \& Schrock, J. (2008). the Role of Emotion in Teaching and Learning History: A Scholarship of Teaching Exploration. The History Teacher, 41(4) August.

Clark, A. \& Chalmers, D. (1998). The Extended Mind. Analysis, 58(1) 7-19, OUP. 
Dourish, P. (2001). Where the action is: the foundations of embodied interaction. Cambridge, MA: The MIT Press.

Farman, J. (2012). Mobile interface theory: Embodied space and locative media. Routledge.

Goodwin, C. (2000). Action and embodiment within situated human interaction Journal of Pragmatics 32(10) 1489-1522.

Haydn, T. (1999). Teaching children about time: back to basics? In R. Phillips and G. Easdown (Eds.) History Education: Subject Knowledge, Pedagogy and Practice, 117-130. Lancaster: Standing Conference of History Teacher Educators in the United Kingdom.

Herodotou, C., Villasclaras-Fernández, E., \& Sharples, M. (2014). Scaffolding citizen inquiry science learning through the nQuire toolkit. Proceedings of EARLI SIG 20: Computer Supported Inquiry Learning, August 18-20, Malmö, Sweden.

Huizenga, J., Admiraal, W., Akkerman, S. \& ten Dam, G. (2009). Mobile game-based learning in secondary education: engagement, motivation and learning in a mobile city game. Journal of Computer Assisted Learning, 25, 332-344.

Hwang, G. (2013). Mindtools for Supporting Mobile-Learning Activities. In Z. Berge \& L. Muilenburg (eds) Routledge Handbook of Mobile Learning, (pp. 155-164). New York: Routledge.

Järvelä, S., Näykki, P., Laru, J., \& Luokkanen, T. (2007). Structuring and regulating collaborative learning in higher education with wireless networks and mobile tools. Educational Technology \& Society, 10(4), 71-79.

Jewitt, C. (2014). Handbook of Multimodal Analysis. London: Routledge.

Jones, O., Williams, M., Fleuriot, C. (2003). Wearable Computing And The Geographies Of Urban Childhood: Working With Children To Explore The Potential Of New Technology. 
In Proceedings of the 2nd International Conference for Interaction Design and Children. 111-118.

Jones, A. L. (2010). Emotional factors in history learning via digital history narrative creation PhD Thesis. Retrieved from http://ir.uiowa.edu/cgi/viewcontent.cgi?article=3474\&context=etd

Klopfer, E., \& Squire, K. (2008). Environmental Detectives - the development of an augmented reality platform for environmental simulations. Educational Technology Research and Development, 56(2), 203-228.

Kress, G. (2010). Multimodality. London: Routledge.

Kress, G. \& van Leeuwen, T. (1996). Reading Images. London: Routledge.

Lombardi, M. (2007). Authentic Learning for the 21st Century: An Overview. Educause Learning Initiative. Retrieved from https://net.educause.edu/ir/library/pdf/ELI3009.pdf

Martín, S., Díaz, G., Cáceres, M., Gago, D., \& Gibert, M. (2012). A mobile augmented reality gymkhana for improving technological skills and history learning: Outcomes and some determining factors. In World Conference on E-Learning in Corporate, Government, Healthcare, and Higher Education, 260-265.

Manovich, L. (2002). The poetics of augmented space: Learning from Prada. Retrieved March 2015 from http://manovich.net/index.php/projects/the-poetics-of-augmented-space

McCullough, M. (2006). On the Urbanism of Locative Media. Places, 18(2), 26. Retrieved from http://escholarship.org/uc/item/84x6m3nf

Milgram, P., \& Colquhoun, H., Jr. (1999). A taxonomy of real and virtual world display integration. In Y. Ohta \& H. Tamura (Eds.) Mixed reality: Merging real and virtual worlds, (pp. 5-28). New York: Springer. 
Mills, K., Comber, B. \& Kelly, P. (2013). Sensing place: Embodiment, sensoriality, kinesis, and children behind the camera. English Teaching: Practice and Critique, 12(2) 11-27.

Milrad, M., Wong, L., Sharples, M., Hweng, G., Looi, C. \& Ogata, H. (2013). Seamless Learning: An International Perspective on Next-Generation Technology-Enhanced Learning. In Z. Berge \& L. Muilenburg (eds) Routledge Handbook of Mobile Learning, (pp. 95-108). New York: Routledge.

Norris C. \& Soloway, E. (2013). Substantive Educational Change is in the Palm of Our Children's Hands. In Z. Berge \& L. Muilenburg (eds) Routledge Handbook of Mobile Learning, (pp. 109-118). New York: Routledge.

Price, S., Sheridan, J., Pontual Falcao, T. \& Roussos, G. (2008). Towards a framework for investigating tangible environments for learning. International Journal of Arts and Technology: Special Issue on Tangible and Embedded Computing , 1(3/4), 351-368.

Rogers, Y., \& Price, S. (2008). The role of mobile devices in facilitating collaborative inquiry in situ. Research and Practice in Technology Enhanced Learning, 3(3), 209 - 229.

Rowlands, M. (2010). The New Science of the Mind: From Extended Mind to Embodied Phenomenology, Cambridge, MA: MIT Press, 2010

Streek, J., Goodwin, C, \& LeBaron, C. (2011). Embodied interaction in the material world: An introduction, In (eds) J. Streek, C. Goodwin, \& C. LeBaron, Embodied Interaction: Language and body in the material world, Cambridge University Press: New York.

Vogel, B., Spikol, D., Kurti, A., \& Milrad, M. (2010). Integrating mobile, web and sensory technologies to support inquiry-based science learning. In Wireless, Mobile and Ubiquitous Technologies in Education (WMUTE), 2010 6th IEEE International Conference 65-72. 
Williams, M., Jones, O., Fleuriot, C. \& Wood, L. (2005). Children and Emerging Wireless Technologies: Investigating the Potential for Spatial Practice. In Proceedings of CHI 2005 819-828.

Winters, N. \& Mor, Y. (2008). CoMo: Supporting collaborative groupwork using mobile phones in distance education. Final Report, Centre for Distance Education, University of London 